\title{
Administration of Gemcitabine for Metastatic Adenocarcinoma during Pregnancy: A Case Report and Review of the Literature
}

\author{
M. Wiesweg, $\mathrm{MD}^{1}$ \\ S. Aydin, MD, PhD² \\ A. Koeninger, $\mathrm{MD}^{3}$ \\ A. Stein, $\mathrm{MD}^{4}$ \\ U. Schara, MD ${ }^{5}$ \\ C. van Roye, $M^{6}$ \\ J. Hense, $M D^{1}$ \\ A. Welt, MD ${ }^{1}$ \\ M. Schuler, MD ${ }^{1}$
}

${ }^{1}$ Department of Medical Oncology, West German Cancer Center, University Hospital Essen, University Duisburg-Essen, Essen, Germany

2 Dipartimento di Ematologia ed Oncologia, Azienda ospedaliera Città

Address for correspondence Marcel Wiesweg, MD, Department of Medical Oncology, West German Cancer Center, University Hospital Essen, Hufelandstrasse 55, 45122 Essen, Germany

della Salute e della Scienza di Torino, Torino, Italy

3 Department of Gynecology and Obstetrics, University Hospital Essen, University Duisburg-Essen, Essen, Germany

${ }^{4}$ Department of Neonatology, Clinic for Pediatrics I, University Hospital Essen, University Duisburg-Essen, Essen, Germany

${ }^{5}$ Department of Neuropediatrics, Developmental Neurology and Social Pediatrics, Clinic for Pediatrics I, University Hospital Essen, University Duisburg-Essen, Essen, Germany

${ }^{6}$ Hematology/Oncology Group Practice, Koblenz, Germany

Am J Perinatol Rep 2014;4:17-22.

\begin{abstract}
Keywords

- gemcitabine

- pregnancy

- adenocarcinoma

- cholangiocarcinoma

- chemotherapy

We present the case of a 38-year-old woman diagnosed with metastatic adenocarcinoma of the biliary tract in the 18th week of pregnancy. Chemotherapy based on cisplatin and gemcitabine was administered, reaching disease stabilization until late-preterm delivery at $35+0$ weeks of gestation. The infant was healthy and showed no malformations. Her head circumference was small, yet no neurological and behavioral defects have been detected. Development was normal during 14 months of follow-up. We discuss the implications of metastatic cancer in pregnancy with focus on therapeutic options for metastatic adenocarcinoma of the biliary tract. In this context, available data for the active regimens in biliary tract cancers-platinum compounds and gemcitabine-are discussed. This report is the fourth in the literature detailing the application of gemcitabine during pregnancy and the first presenting longer term follow-up, complementing available evidence that gemcitabine-based regimens are feasible in this situation.
\end{abstract}

Cancer is diagnosed in approximately 1 in 1,000 pregnancies, ${ }^{1}$ constituting a major disruption in the life of the pregnant woman and her family. Advanced disease stages requiring systemic therapy invariably lead the treating physicians into an ethical dilemma: two lives are at risk. Administering the cancer treatment to the mother may harm the unborn child as it is exposed to cytostatic drugs. On the contrary, omitting therapy will deny necessary treatment to the mother, but the unborn child will also carry the risk of prematurity if the disease progresses rapidly. Once the decision is taken to accept this risk and to start chemotherapy, the choice of possible regimens will not only be based on their expected anticancer activity but also on available experience regarding fetotoxic effects.

Due to the typical age distribution and standardized examination protocols in pregnancy, gynecologic cancers received

October 8, 2013 accepted after revision December 17, 2013

published online

February 17, 2014
DOI http://dx.doi.org/ 10.1055/s-0034-1368091. ISSN 2157-6998.
Copyright $\odot 2014$ by Thieme Medical Publishers, Inc., 333 Seventh Avenue, New York, NY 10001, USA. Tel: +1(212) 584-4662.
License terms

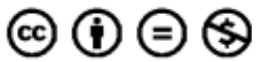


predominate in the literature. Larger case series and broader experience with systemic therapy, in some cases even guidelines, exist for breast, ${ }^{2,3}$ cervical and ovarian ${ }^{4}$ cancer, as well as lymphoma ${ }^{5}$ and lung cancer. ${ }^{6}$ An observational study of the long-term development of 70 children exposed to chemotherapy during fetal development neither showed an increase in central nervous system, cardiac, or auditory morbidity nor impairments of general health and growth. ${ }^{7}$ This study demonstrates that for a spectrum of anticancer agents, therapy during pregnancy is possible with excellent results for mother and child.

Biliary tract cancers include gall bladder carcinoma and cholangiocarcinoma (bile duct carcinoma), the latter comprising intrahepatic, hilar, and extrahepatic bile duct carcinomas. ${ }^{8}$ These entities form a group of related diseases with diverse biological properties and molecular characteristics. Due to their relative rarity, biliary tracts cancers usually are considered as a combined entity in retrospective analyses and clinical trials. ${ }^{9}$ In the United States, approximately 2,500 cases of cholangiocarcinoma are reported per year. ${ }^{10}$ The incidence has been rising over the last decades, ${ }^{11}$ particularly for the case of intrahepatic cholangiocarcinoma. ${ }^{12}$ Prognosis is poor, and even if aggressive resection is possible, 5-year survival rates of no more than 20 to $40 \%$ are reported. ${ }^{8}$ In case of unresectable or metastatic disease, median survival of 14 to 15 months is described in recent large retrospective cohorts. ${ }^{12,13}$

Multiple studies of advanced biliary tract cancers have shown a benefit of chemotherapy over best supportive care. ${ }^{14}$ In a randomized study of gemcitabine/oxaliplatin (Gemox), 5-fluorouracil (5-FU), or best supportive care, the Gemox regimen was clearly superior regarding overall and progression-free survival. ${ }^{15}$ A pooled analysis of over 100 phase II studies $^{16}$ and a large Japanese retrospective study ${ }^{17}$ consistently identified two key compounds showing efficacy in biliary tract cancer: gemcitabine and platinum. A large British phase III study, ${ }^{18}$ later confirmed by a Japanese multicenter trial, ${ }^{19}$ could show a significant overall survival benefit for the combination of gemcitabine and cisplatin versus gemcitabine alone. Thus, a regimen consisting of a platinum compound and gemcitabine is currently considered as the appropriate and evidence-based choice for the treatment of advanced biliary tract cancer.

\section{Case Report}

A 38-year old Caucasian woman, gravida 2 para 1, in the 15th week of pregnancy, was admitted for treatment of diabetes mellitus at a regional hospital. She complained of back pain, saddle anesthesia, and bowel and bladder dysfunction. She was referred to neurosurgery where an emergency magnetic resonance imaging (MRI) of the lumbosacral spine revealed a $5 \times 3.5 \times 3-\mathrm{cm}$ sacral tumor at S1/S2 with resulting spinal compression (-Fig. 1). Spinal decompression via sacral laminectomy was performed on the same day. Surgery was well tolerated; the neurological symptoms improved but persisted to a lesser degree.

Histopathological examination of the resected bone tumor showed CK7-positive adenocarcinoma. Further immunohis-

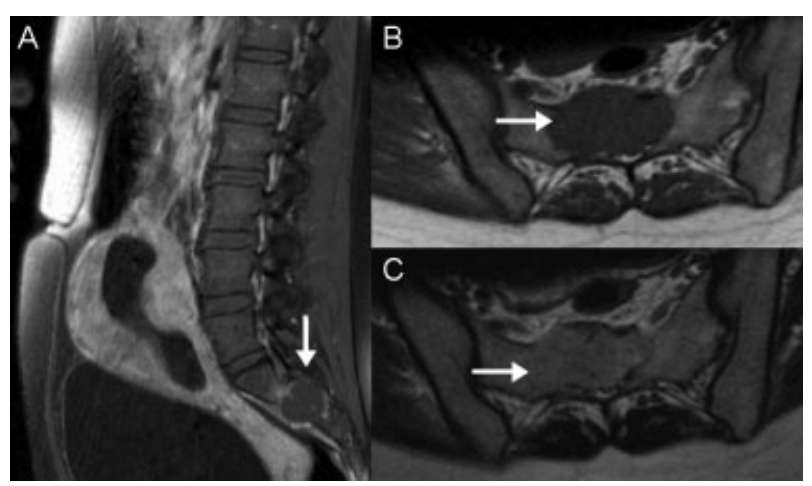

Fig. 1 Lumbar spine magnetic resonance imaging at initial diagnosis. Sacral mass (arrow) (a) sagittal T1, also depicting the pregnancy, (b) transversal T1W TSE, and (c) T2W TSE.

tochemistry was negative, including TTF-1, CK20, CDX-2, estrogen and progesterone receptors, BRST-2, glypican-3, and hepatocyte-specific antigen. Accordingly, the cancer was initially classified as carcinoma of unknown primary (CUP), and a search for the primary tumor via low-dose thoracic computed tomography (CT), breast ultrasonography, mammography, and abdominal MRI was conducted. This revealed a hepatic lesion of $7.4 \times 6 \mathrm{~cm}$ in segments $2 / 3$ and 4 , infiltrating the porta hepatis and resulting in moderate intrahepatic cholestasis, as well as several satellite nodules in segment 8 and suspicious locoregional lymph nodes (-Fig. 2).

In view of the complex situation of metastatic adenocarcinoma and pregnancy, the patient was referred to the West German Cancer Center.

After review of the immunohistochemical profile, MR morphology, and detection of a typical pattern at contrast ultrasonography, which consisted of a hypervascular lesion with early washout, ${ }^{20}$ the most likely primary cancer was a cholangiocellular adenocarcinoma.

Gynecological examination and ultrasound showed an appropriately developed fetus at gestational age of 17 weeks and 6 days.

During the following days, we carefully explained to the patient and her husband the prognosis of metastatic cholangiocellular carcinoma, possible aims for palliative treatment, and the available options and expected side effects of the treatment modalities to both mother and baby. We offered pregnancy interruption to allow maximum treatment of the mother. At the same time, we explained a concept of reaching the limit of viability by prolonging the gestation to a minimum of 24 weeks, deliver the child, and give maximum treatment to the mother at this point.

As the disease, if left untreated, would be expected to progress and could produce deleterious consequences to the mother at a pregnancy stage when the risks of prematurity for the fetus still prevailed, we proposed to administer chemotherapy to gain the weeks necessary for the child to develop.

The patient and her husband decided to preserve the pregnancy and to begin chemotherapy.

We initiated systemic treatment with cisplatin $50 \mathrm{mg} / \mathrm{m}^{2}$ on day 1 and gemcitabine $1,000 \mathrm{mg} / \mathrm{m}^{2}$ on days 1 and 8 of a 


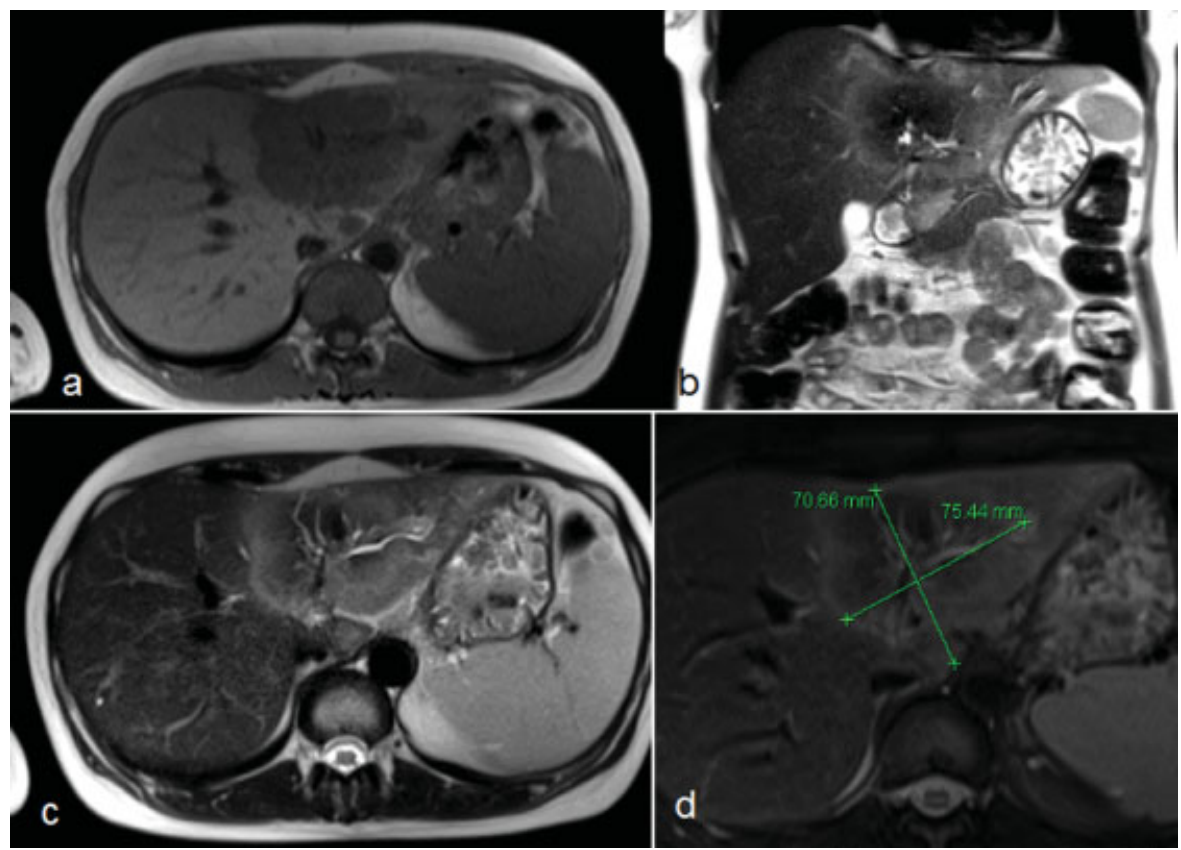

Fig. 2 Abdominal magnetic resonance imaging at initial diagnosis, primary tumor (arrow) (a) transversal T1 FL2D, (b) coronar T2 Haste, (c) transversal T2 Haste, and (d) T2 TSE.

21-day cycle. Therapy was well tolerated; the patient complained of no side effects, especially no nausea or vomiting. Application of day 8 gemcitabine of cycle 2 was delayed by 1 week due to leukocytopenia $(1.4 / \mathrm{nL}$, common terminology criteria for adverse events [CTCAE] grade 2).

Restaging was conducted by ultrasound after 7 weeks of chemotherapy (gestational age $25+1$ ) to minimize prenatal exposure to radiation. This revealed partial remission of the hepatic lesion. An additional MRI of the lumbosacral region detected no signs of recurrent disease in the region of previous surgery. However, a slight progression of a previously very small pelvic metastasis was reported. Most importantly, fetal development at this time proved still appropriate for gestational age (-Table $\mathbf{1}$ ). Due to hematotoxicity it was decided to continue chemotherapy in prolonged cycles of 11 to 12 days, planning a treatment interruption afterward and

Table 1 Fetal biometric and Doppler measurements

\begin{tabular}{|c|c|c|c|}
\hline Weeks of gestation & $25+1$ & $29+0$ & $34+6$ \\
\hline \multirow[t]{2}{*}{ Head circumference } & $221.6 \mathrm{~mm}$ & $261.1 \mathrm{~mm}$ & $303.2 \mathrm{~mm}$ \\
\hline & $\longmapsto+1$ & $\longmapsto 1$ & $\longmapsto \quad 1$ \\
\hline \multirow[t]{2}{*}{ Abdominal circumference } & $204.2 \mathrm{~mm}$ & $224.4 \mathrm{~mm}$ & $273.0 \mathrm{~mm}$ \\
\hline & $\longmapsto \bullet$ & $\mapsto \quad 1 \quad-1$ & 1 \\
\hline \multirow[t]{2}{*}{ Femur length } & $42.8 \mathrm{~mm}$ & $52.6 \mathrm{~mm}$ & $60.0 \mathrm{~mm}$ \\
\hline & $\longmapsto \bullet-1$ & $\longmapsto+1$ & \\
\hline \multirow[t]{2}{*}{ Head to abdomen circumference ratio } & 1.09 & 1.16 & 1.11 \\
\hline & $\longmapsto+$ & $\longmapsto$ & $\longmapsto$ \\
\hline \multirow[t]{2}{*}{ Estimated weight (Hadlock formula) } & $710 \mathrm{~g}$ & $1,084 \mathrm{~g}$ & $1,846 \mathrm{~g}$ \\
\hline & $\longmapsto+1$ & $\longmapsto \bullet$ & 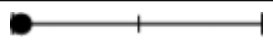 \\
\hline \multirow[t]{2}{*}{ Umbilical artery (pulsatility index) } & 1.51 & 0.93 & \\
\hline & $\longmapsto$ & $\longmapsto$ & \\
\hline \multirow[t]{2}{*}{ Middle cerebral artery (pulsatility index) } & & 1.8 & \\
\hline & & $\longmapsto \quad 1$ & \\
\hline \multirow[t]{2}{*}{ Ductus venosus (pulsatility index) } & & 0.64 & \\
\hline & & $\longmapsto$ & \\
\hline
\end{tabular}


Table 2 Biometric measurements of the infant

\begin{tabular}{|c|c|c|c|}
\hline Corrected age & $30 \mathrm{~d}$ & $5 \mathrm{mo}$ & $12 \mathrm{mo}$ \\
\hline \multirow[t]{2}{*}{ Head circumference } & $31 \mathrm{~cm}$ & $41 \mathrm{~cm}$ & $45 \mathrm{~cm}$ \\
\hline & 0 & $\longmapsto 1$ & $\longmapsto 1$ \\
\hline \multirow[t]{2}{*}{ Body weight } & $2,340 \mathrm{~g}$ & $6,410 \mathrm{~g}$ & $8,250 \mathrm{~g}$ \\
\hline & $0 \quad 1$ & $\longmapsto \quad 1$ & $\mapsto \bullet \quad+$ \\
\hline \multirow[t]{2}{*}{ Body length } & $42 \mathrm{~cm}$ & $63 \mathrm{~cm}$ & $69.7 \mathrm{~cm}$ \\
\hline & 0 & $\longmapsto$ & D- \\
\hline
\end{tabular}

cesarean section at $35+0$ weeks of gestation. Restaging by abdominal ultrasonography in week 29 confirmed partial remission of the hepatic and lymphonodular tumor manifestations. No further imaging was performed at this point, the mother being in excellent clinical condition. Fetal development was also monitored closely. Fetal ultrasound in week 29 raised the suspicion of beginning growth retardation, reflected by a head-to-abdominal circumference asymmetry and decreasing growth velocity (-Table 1). Doppler sonography showed no pathological findings without the signs of placental insufficiency and normal pulsatility indices of the umbilical artery, the middle cerebral artery and the Ductus venosus. After interdisciplinary discussion, it was decided in agreement with the patient and her husband to withhold further chemotherapy. In week $33+2$, fetal examination showed normal interval growth and normal Doppler sonographic findings without the signs of placental insufficiency.

No cancer therapy was given until cesarean section was performed at gestational week $35+0$, delivering a healthy female infant, APGAR 9/10/10, birth weight 1,840 g (20th percentile), length $41 \mathrm{~cm}$ (20th percentile), and head circumference $30 \mathrm{~cm}$ (30th percentile). The baby initially showed labored breathing with retractions but did not require supplemental oxygen, breathing spontaneously at all times. Examination revealed no evidence of gross malformations, neurological or cardiocirculatory abnormalities, and infection or bone marrow suppression (leukocytes $6.85 / \mathrm{nL}$, hemoglobin $14.5 \mathrm{~g} / \mathrm{dL}$, and platelets 320/nL). Supplemental enteral feeding via nasogastric tube was necessary for 10 days. The baby was discharged from the hospital in very good general condition 1 month after her birth. Weight was 2,340 g ( $<$ third percentile), height $42 \mathrm{~cm}$ ( $<$ third percentile), and head circumference $31 \mathrm{~cm}$ ( $<$ third percentile).

The mother underwent restaging examinations after delivery. Confirming our clinical impression during the previous weeks, bone metastases of the frontotemporal cranium, ribs, and ilium were revealed by bone scintigraphy and cranial $\mathrm{CT}$. Abdominal MRI confirmed progressive disease in the liver and bone metastases with large soft tissue components. Chemotherapy with cisplatin and gemcitabine was resumed, palliative local radiotherapy administered to the sacrum, ilium, and femoral neck at a total dose of $20 \mathrm{~Gy}$, and bisphosphonate therapy initiated.

Only 2 weeks after the completion of the radiotherapy, disease progressed with new vertebral, mediastinal, and pulmonary metastases. Thus, second-line chemotherapy with 5-FU, folic acid, and oxaliplatin was initiated. Thirdline therapy with paclitaxel was not tolerated due to severe polyneuropathy. Hence, weekly epirubicin was administered as fourth-line therapy. Fourteen months after the initial diagnosis massive progression of pulmonary, hepatic and bone metastases occurred. The patient died shortly afterward.

A pediatric follow-up examination of the infant after a corrected age of 5 months confirmed normal physical and neurological development. In a second examination at a corrected age 12 months, development was found again appropriate for her age, with length at $1 \mathrm{~cm}$ below 3rd percentile and weight at the 10 th percentile. The neuropediatric examination showed no abnormal findings. Biometry measurements are presented in - Table 2.

\section{Discussion}

In the case presented here, a pregnant woman with newly diagnosed metastatic adenocarcinoma required palliative cancer therapy with the intention of preserving the pregnancy and withholding harm from the child. Formally classified as CUP, histopathology and imaging workup provided evidence for biliary tract cancer. Recent molecular analyses placed the tissue of origin of a larger share of CUP in this region, ${ }^{21}$ supporting the working diagnosis. Thus, based on available evidence, platinum compounds and gemcitabine evolved as appropriate anticancer agents. Biliary tract cancers during pregnancy have rarely been described in the literature. None of the five case reports available $22-26$ mentions the application of chemotherapy.

Cisplatin can be given during pregnancy based on relatively broad experience, typically with ovarian, ${ }^{4}$ and lung cancer. ${ }^{6}$ A review lists 36 cases with moderate fetomaternal toxicity and no clear causative link to malformations, albeit platinum-DNA adducts can be detected in exposed neonates. ${ }^{27}$ With regard to oxaliplatin, only a single case report was found in the literature, ${ }^{28}$ which reports no fetal toxicity.

Gemcitabine is a nucleoside analogue replacing cytidine during DNA replication and inhibiting ribonucleotide reductase. ${ }^{29}$ In the rat, full placental transfer of the drug and high fetal exposure could be shown. ${ }^{30}$ Developmental toxicity has been evaluated in mice. ${ }^{31}$ Malformations, reduced prenatal and neonatal survival, and weight changes could be detected, yet only in those animals receiving the drug in excessive doses. From preclinical data, it can thus be expected that a 
Table 3 Case reports of gemcitabine administration during pregnancy

\begin{tabular}{|c|c|c|c|c|}
\hline Reference & Kim et $\mathrm{al}^{32}$ & $\begin{array}{l}\text { Gurumurthy } \\
\text { et } \mathrm{al}^{33}\end{array}$ & Boyd et $\mathrm{al}^{34}$ & This report \\
\hline Therapy protocol & $\begin{array}{l}\text { Gemcitabine } 1,250 \mathrm{mg} / \mathrm{m}^{2} \\
\mathrm{~d} 1+8 \text {, cisplatin } 35 \mathrm{mg} / \mathrm{m}^{2} \\
\mathrm{~d} 1+8, \mathrm{q} 3 \mathrm{w}\end{array}$ & $\begin{array}{l}\text { Gemcitabine } \\
1,000 \mathrm{mg} / \\
\mathrm{m}^{2} \mathrm{~d} 1+8, \\
\text { carboplatin } \\
\text { AUC } \\
5 \mathrm{~d} 1, \text { q3w }\end{array}$ & $\begin{array}{l}\text { Gemcitabine weekly } \\
\text { (exact dose not given) }\end{array}$ & $\begin{array}{l}\text { Gemcitabine } \\
1,000 \mathrm{mg} / \mathrm{m}^{2} \\
\mathrm{~d} 1+8, \\
\text { cisplatin } 50 \mathrm{mg} / \mathrm{m}^{2} \\
\mathrm{~d} 1, \mathrm{q} 3 \mathrm{w} \text {, later } \\
\text { prolonged } \\
\text { intervals }\end{array}$ \\
\hline Gestational age & Approximately $17-22$ & 25 & $24-32$ & $18+1-27+6$ \\
\hline $\begin{array}{l}\text { Cumulative } \\
\text { gemcitabine dose }\end{array}$ & $5 \mathrm{~g} / \mathrm{m}^{2}$ & $2 \mathrm{~g} / \mathrm{m}^{2}$ & $\geq 6 \mathrm{~g} / \mathrm{m}^{2}$ & $5 \mathrm{~g} / \mathrm{m}^{2}$ \\
\hline $\begin{array}{l}\text { Additional therapy } \\
\text { during pregnancy }\end{array}$ & $\begin{array}{l}\text { Cerebral metastasectomy } \\
\text { Whole brain irradiation ( } 30 \mathrm{~Gy} \text { ) } \\
\text { Docetaxel } 40 \mathrm{~g} / \mathrm{m}^{2} \mathrm{~d} 1+8 \text { and } \\
\text { cisplatin } 35 \mathrm{mg} / \mathrm{m}^{2} \mathrm{~d} 1+8 \text {, q3w }\end{array}$ & - & Pancreaticoduodenectomy & $\begin{array}{l}\text { Sacral } \\
\text { laminectomy }\end{array}$ \\
\hline
\end{tabular}

Abbreviation: AUC, area under curve.

fetus is exposed to the drug in utero. When gemcitabine is administered in established therapeutic doses overt developmental toxicities to the fetus may be limited.

Three previous clinical cases describing the administration of a gemcitabine-containing chemotherapy are found in the literature (-Table $\mathbf{3}$ ).

The first report by Kim et $\mathrm{al}^{32}$ described a 35-year old Korean woman with metastatic pulmonary adenocarcinoma and an unrecognized pregnancy who received whole brain irradiation, four cycles of cisplatin and docetaxel, and secondline therapy with two cycles of cisplatin and gemcitabine before the pregnancy was detected on CT scan at a gestational age of 31 weeks. The infant was delivered at week 33 with no evidence of malformation, showing normal development.

In a second report, Gurumurthy et $\mathrm{al}^{33}$ administered one cycle of gemcitabine and carboplatin to a 38-year-old Caucasian woman with advanced non-small-cell lung carcinoma and poor performance status. The infant was delivered at $28+4$ weeks of gestation and suffered from anemia, respiratory distress requiring ventilator support, Staphylococcus aureus sepsis and pulmonary infection. The child developed chronic lung disease and required long-term oxygen support.

A third case report by Boyd et $\mathrm{al}^{34}$ described the application of two 4-weekly cycles of gemcitabine starting at week 24 of pregnancy as additive therapy after the resection of pancreatic adenocarcinoma. A healthy child was born after induction of labor at week 34. Further follow-up of the infant is not reported.

In the report by Kim et al, pregnancy was unknown when treatment was initiated. As early as in the first trimester, the fetus was exposed to three different chemotherapeutics, including a cumulative dose of $5 \mathrm{~g} / \mathrm{m}^{2}$ gemcitabine (approximately gestational weeks 17-22), and even distant irradiation therapy, resulting in no apparent toxicity or abnormalities of the infant. Although the longterm outcome of the child is not known, this report is a good example that chemotherapy is feasible during pregnancy.
But due to the multimodal exposure, any toxicity which may still develop during follow-up would not clearly be attributable to a particular drug.

Only one course of chemotherapy was administered in the report of Gurumurthy et al (cumulative dose $2 \mathrm{~g} / \mathrm{m}^{2}$ gemcitabine, week 25). The deteriorating condition of the mother forced a preterm birth, the child subsequently suffering from multiple severe complications of prematurity. It is thus impossible to attribute aspects of the infant's outcome to gemcitabine.

In the report of Boyd et al, gemcitabine was administered in a high-risk, formally adjuvant situation. Nevertheless, hepatic metastases developed shortly afterward. Within the limited follow-up, no toxicities to the child were reported.

The present case, to our knowledge the fourth report in the literature, details the clinical course of the application of a gemcitabine/cisplatin-based regimen during pregnancy. Treatment was initiated by deliberate decision of the patient with the knowledge of the pregnancy. Decision making was supported by a literature survey and extensive discussion with the patient and her husband.

We decided to administer chemotherapy with the intention of achieving the best possible treatment response to prolong the gestation to at least the limit of viability. Although relatively broad experience is available for cisplatin treatment during pregnancy, the decision to initiate gemcitabine-based chemotherapy was essentially based on preclinical data and the first two case reports discussed above. Treatment was well tolerated, and delivery could be successfully postponed until the late-preterm stage. The head circumference of the neonate was small, but under ongoing neuropediatric surveillance there has been no evidence of malformations or neurodevelopmental disorders of the child. In summary, our report adds to the evidence that administration of gemcitabine-based chemotherapy is feasible during pregnancy. We complement the emerging view that in the complex setting of cancer diagnosis during pregnancy, chemotherapy can be 
applied to avoid the possible severe and long-term complications of prematurity. ${ }^{7}$ This seems preferable to the induction of preterm delivery to avoid the hypothetical consequences and complications of chemotherapy.

\section{Acknowledgment}

Publication fees were supported by the Deutsche Forschungsgemeinschaft Open-Access Publishing Programme.

\section{References}

1 Pavlidis NA. Coexistence of pregnancy and malignancy. Oncologist 2002;7(4):279-287

2 Amant F, Loibl S, Neven P, Van Calsteren K. Breast cancer in pregnancy. Lancet 2012;379(9815):570-579

3 Amant F, Deckers S, Van Calsteren K, et al. Breast cancer in pregnancy: recommendations of an international consensus meeting. Eur J Cancer 2010;46(18):3158-3168

4 Morice P, Uzan C, Gouy S, Verschraegen C, Haie-Meder C. Gynaecological cancers in pregnancy. Lancet 2012;379(9815):558-569

5 Evens AM, Advani RH, Lossos IS, et al. Lymphoma in Pregnancy: Excellent Fetal Outcomes and Maternal Survival in a Large Multicenter Analysis. Paper presented at: ASH Annual Meeting; San Diego; December 11, 2011

6 Azim HA Jr, Peccatori FA, Pavlidis N. Lung cancer in the pregnant woman: to treat or not to treat, that is the question. Lung Cancer 2010;67(3):251-256

7 Amant F, Van Calsteren K, Halaska MJ, et al. Long-term cognitive and cardiac outcomes after prenatal exposure to chemotherapy in children aged 18 months or older: an observational study. Lancet Oncol 2012;13(3):256-264

8 Benson AB III, Abrams TA, Ben-Josef E, et al. Hepatobiliary cancers clinical practice guidelines in oncology. J Natl Compr Canc Netw 2009;7(4):350-391

9 Romiti A, D'Antonio C, Zullo A, et al. Chemotherapy for the biliary tract cancers: moving toward improved survival time. J Gastrointest Cancer 2012;43(3):396-404

10 de Groen PC, Gores GJ, LaRusso NF, Gunderson LL, Nagorney DM. Biliary tract cancers. N Engl J Med 1999;341(18):1368-1378

11 Khan SA, Thomas HC, Davidson BR, Taylor-Robinson SD. Cholangiocarcinoma. Lancet 2005;366(9493):1303-1314

12 Endo I, Gonen M, Yopp AC, et al. Intrahepatic cholangiocarcinoma: rising frequency, improved survival, and determinants of outcome after resection. Ann Surg 2008;248(1):84-96

13 Eckmann KR, Patel DK, Landgraf A, et al. Chemotherapy outcomes for the treatment of unresectable intrahepatic and hilar cholangiocarcinoma: a retrospective analysis. Gastrointest Cancer Res 2011;4(5-6):155-160

14 Furuse J, Kasuga A, Takasu A, Kitamura H, Nagashima F. Role of chemotherapy in treatments for biliary tract cancer. J Hepatobiliary Pancreat Sci 2012;19(4):337-341

15 Sharma A, Dwary AD, Mohanti BK, et al. Best supportive care compared with chemotherapy for unresectable gall bladder cancer: a randomized controlled study. J Clin Oncol 2010;28(30):4581-4586

16 Eckel F, Schmid RM. Chemotherapy in advanced biliary tract carcinoma: a pooled analysis of clinical trials. Br J Cancer 2007; 96(6):896-902
17 Yonemoto N, Furuse J, Okusaka T, et al. A multi-center retrospective analysis of survival benefits of chemotherapy for unresectable biliary tract cancer. Jpn J Clin Oncol 2007;37(11):843-851

18 Valle J, Wasan H, Palmer DH, et al; ABC-02 Trial Investigators. Cisplatin plus gemcitabine versus gemcitabine for biliary tract cancer. N Engl J Med 2010;362(14):1273-1281

19 Okusaka T, Nakachi K, Fukutomi A, et al. Gemcitabine alone or in combination with cisplatin in patients with biliary tract cancer: a comparative multicentre study in Japan. Br J Cancer 2010;103(4): 469-474

20 Bohle W, Clemens P, Heubach T, Zoller W. Contrast-enhanced ultrasound (CEUS) for differentiating between hepatocellular and cholangiocellular carcinoma. Ultraschall Med - Eur J Ultrasound 2011;33:191-195

21 Hainsworth JD, Rubin MS, Spigel DR, et al. Molecular gene expression profiling to predict the tissue of origin and direct site-specific therapy in patients with carcinoma of unknown primary site: a prospective trial of the Sarah Cannon research institute. J Clin Oncol 2013;31(2):217-223

22 Purtilo DT, Clark JV, Williams R. Primary hepatic malignancy in pregnant women. Am J Obstet Gynecol 1975;121(1):41-44

23 Devoe LD, Moossa AR, Levin B. Pregnancy complicated by extrahepatic biliary tract carcinoma. A case report. J Reprod Med 1983; 28(2):153-155

24 Balderston KD, Tewari K, Azizi F, Yu JK. Intrahepatic cholangiocarcinoma masquerading as the HELLP syndrome (hemolysis, elevated liver enzymes, and low platelet count) in pregnancy: case report. Am J Obstet Gynecol 1998;179(3 Pt 1):823-824

25 Sadoon S, Hodgett S. Unusual cause of itching in a pregnancy (cholangiocarcinoma). J Obstet Gynaecol 2008;28(2):230-231

26 Marasinghe JP, Karunananda SA, Angulo P. Cholangiocarcinoma in pregnancy: a case report. J Obstet Gynaecol Res 2008;34(4 Pt 2): 635-637

27 Mir O, Berveiller P, Ropert S, Goffinet F, Goldwasser F. Use of platinum derivatives during pregnancy. Cancer 2008;113(11): 3069-3074

28 Gensheimer M, Jones CA, Graves CR, Merchant NB, Lockhart AC. Administration of oxaliplatin to a pregnant woman with rectal cancer. Cancer Chemother Pharmacol 2009;63(2): 371-373

29 Cerqueira NMFSA, Fernandes PA, Ramos MJ. Understanding ribonucleotide reductase inactivation by gemcitabine. Chemistry 2007;13(30):8507-8515

30 Esumi Y, Mitsugi K, Seki H, Takao A, Kawai M. Placental transfer, lacteal transfer and plasma protein binding of gemcitabine. Xenobiotica 1994;24(10):957-964

31 Eudaly JA, Tizzano JP, Higdon GL, Todd GC. Developmental toxicity of gemcitabine, an antimetabolite oncolytic, administered during gestation to CD-1 mice. Teratology 1993;48(4):365-381

32 Kim JH, Kim HS, Sung CW, Kim KJ, Kim CH, Lee KY. Docetaxel, gemcitabine, and cisplatin administered for non-small cell lung cancer during the first and second trimester of an unrecognized pregnancy. Lung Cancer 2008;59(2):270-273

33 Gurumurthy M, Koh P, Singh R, et al. Metastatic non-small-cell lung cancer and the use of gemcitabine during pregnancy. J Perinatol 2009;29(1):63-65

34 Boyd CA, Benarroch-Gampel J, Kilic G, Kruse EJ, Weber SM, Riall TS. Pancreatic neoplasms in pregnancy: diagnosis, complications, and management. J Gastrointest Surg 2012;16(5): $1064-1071$ 